\title{
ARGUMENTOS FRONTEADOS NA PERIFERIA À ESQUERDA DE ORAÇÕES CONDICIONAIS CENTRAIS NO PORTUGUÊS BRASILEIRO: UM PROCESSO DE CLITIC LEFT DISLOCATION COM RETOMADA PRONOMINAL VISÍVEL OU NULA
}

\section{FRONTED ARGUMENTS IN THE LEFT PERIPHERY OF CENTRAL CONDITIONAL SENTENCES IN BRAZILIAN PORTUGUESE: A CLITIC LEFT DISLOCATION PROCESS WITH VISIBLE OR NULL RESUMPTIVE PRONOUNS}

\author{
Vanessa Leme Fadel Steinhauser ${ }^{*}$ \\ UEM
}

\section{André Antonelli**}

UEM

Resumo: Haegeman (2012) observa que, em orações condicionais centrais em inglês, não pode haver topicalização de argumento. Em sua análise, a autora propõe que o movimento do argumento para a periferia da sentença bloqueia o alçamento do operador condicional de TP para CP. Em português, diferentemente do inglês, é possível o fronteamento de argumentos. Para explicar essa diferença, propomos que, em português, quando há fronteamento de argumento em orações condicionais, o elemento fronteado é um constituinte gerado diretamente na periferia à esquerda. Nossa proposta é que tais sintagmas deslocados são retomados por um pronome visível ou nulo, tendo em vista o fato de o português ser uma língua de objeto nulo (CYRINO, 1994). Nesse sentido, as construções de fronteamento em orações condicionais do português brasileiro são, portanto, estruturas com deslocamento à esquerda clítica (Clitic Left Dislocation - CLLD), já que não houve movimento do elemento fronteado. O fato de não haver movimento sintático do argumento topicalizado tornaria possível o alçamento do operador condicional para o sistema CP.

Palavras-Chave: Fronteamento. CLLD. Objeto nulo. Orações condicionais.

Abstract: Haegeman (2012) observes that, in central conditional sentences in English, there can be no argument topicalization. In her analysis, the author proposes that the argument fronting to the periphery

\footnotetext{
* Mestranda no Programa de Pós-Graduação em Letras da Universidade Estadual de Maringá (UEM). ORCID: https://orcid. org/0000-0001-6911-5031. E-mail: vanessalemefs@hotmail.com.

** Doutor em Linguística pela Universidade Estadual de Campinas (UNICAMP). Professor Adjunto da Universidade Estadual de Maringá (UEM). ORCID: https://orcid.org/0000-0002-7896-5465. E-mail: alantonelli@uem.br.
} 
of the sentence is the factor responsible for blocking the raising of the conditional operator from TP to CP. In Portuguese, unlike English, it is possible the fronting of arguments. In order to account for this difference, we propose that, in Portuguese, when there is argument fronting in conditional sentences, the fronted constituent is a phrase directly merged in the left periphery. Our proposal is that such elements are coreferential of a visible or null pronoun, considering that Portuguese is a language which allows null objects (CYRINO, 1994). Under this approach, fronting structures in conditional sentences in Brazilian Portuguese are, therefore, clauses manifesting Clitic Left Dislocation (CLLD), since there was no movement of the fronted constituent. Thus, the absence of syntactic raising of topicalized phrase makes it possible the movement of the conditional operator to the CP system.

Keywords: Fronting. CLLD. Null object. Conditional sentences.

\section{INTRODUÇÃO}

O presente trabalho tem como objetivo explicar uma diferença sintática entre orações adverbiais do português e do inglês. Ao estudar o fronteamento de constituintes na língua inglesa, Haegeman (2012, p. 217) mostra que, em orações condicionais centrais introduzidas pela conjunção “if” (em português, se), não pode haver topicalização de argumento para a periferia da sentença, como ilustrado em (1).

(1) *If the exams you don't pass, you won't get the degree.

Em inglês, pode-se ter na periferia de orações condicionais centrais apenas adjuntos, como exemplificado em (2) (HAEGEMAN, 2012, p. 217).

(2) If on Monday the share price is still at the current level, then clearly their defence doesn't hold much water.

No português brasileiro (doravante PB), ao contrário do inglês, é possível o fronteamento tanto de argumentos (3) quanto de adjuntos (4).

(3) Se essas atividades você não fizer, você não vai sair com a gente.

(4) Se amanhã você não fizer essas atividades, você não vai sair com a gente.

Em sua análise, Haegeman propõe que o movimento do argumento para a periferia da sentença é o responsável por bloquear o alçamento do operador condicional de TP para CP nas condicionais em inglês. Assumindo os pressupostos da autora, explicamos a diferença de comportamento no PB, propondo que, em português, quando há fronteamento de argumento em orações condicionais centrais introduzidas por "se", o elemento fronteado na realidade corresponde a um constituinte gerado diretamente na periferia à esquerda. Nossa proposta é que tais sintagmas deslocados são retomados ou por um pronome visível ou por um pronome nulo, tendo em vista o fato de o português ser uma língua de objeto nulo (CYRINO, 1994). Nesse sentido, as construções de fronteamento em orações condicionais centrais do PB são, na realidade, estruturas com deslocamento à esquerda clítica (Clitic Left Dislocation - CLLD), já que não houve movimento do elemento fronteado. $\mathrm{O}$ fato de não haver movimento sintático do argumento topicalizado tornaria possível o alçamento do operador condicional para o sistema $\mathrm{CP}$, diferentemente do que ocorre em inglês.

Assim sendo, este texto encontra-se organizado da seguinte maneira. Inicialmente, apresentamos alguns pontos que fundamentam nossa análise teórica, tais como a noção de CP 
cindido, as diferenças entre Topicalização (Top) e Deslocamento à Esquerda (DE), o licenciamento de objeto nulo no PB e as propriedades de fronteamento de argumentos. Na sequência, apresentamos nossa proposta de análise para os dados do PB que se distinguem do inglês. Por fim, na última seção, tecemos algumas considerações finais.

\section{O CP CINDIDO}

Em seu trabalho pioneiro sobre a periferia da sentença, Rizzi (1997) propõe a decomposição da categoria CP em várias projeções, cada uma delas codificando uma propriedade específica. Em (5), apresentamos a periferia cindida defendida pelo autor.

(5)

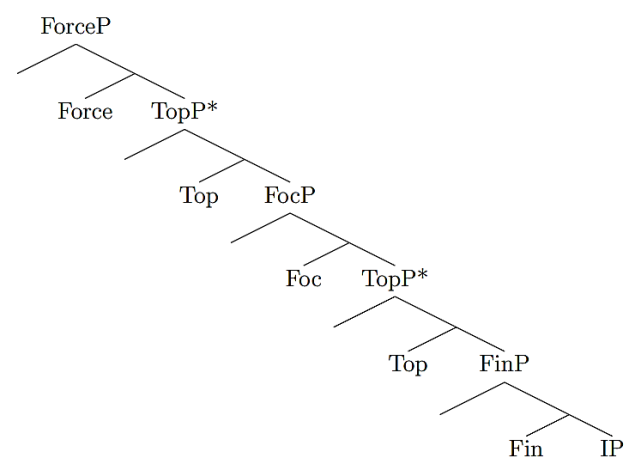

Rizzi argumenta que a periferia à esquerda da sentença é constituída por quatro projeções principais, que apresentam um valor estrutural ou semântico/pragmático específico. Em ForceP, seriam codificadas as informações referentes à força ilocucionária da sentença, informando, por exemplo, se uma determinada cláusula é declarativa, interrogativa, imperativa ou exclamativa; em FinP, estariam codificadas as propriedades de finitude da oração. Essas duas projeções seriam responsáveis por estabelecer uma interface com o conteúdo proposicional (expresso por IP), função esta que seria desempenhada por FinP, e com uma estrutura superordenada (uma oração superior, ou a articulação do discurso, no caso de uma oração principal), função desempenhada por ForceP.

Entre FinP e ForceP, haveria projeções sintáticas de natureza discursiva, a saber: FocusP e TopP. A primeira hospedaria elementos focalizados e estaria posicionada entre as projeções TopP, as quais possuem natureza recursiva (indicado com asterisco na representação arbórea) e abrigam constituintes topicalizados. Por conta de sua natureza pragmático-discursiva, as projeções TopP e FocP seriam projetadas apenas nos casos em que a derivação apresenta um constituinte topicalizado ou focalizado.

\section{TOPICALIZAÇÃO VERSUS DESLOCAMENTO À ESQUERDA (CLÍTICA)}

Na literatura linguística especializada, as construções de tópico usualmente são subdivididas em dois grandes grupos: i) aquelas em que o elemento deslocado não apresenta um pronome cópia, que seriam as estruturas de Topicalização (TopP); e ii) aquelas em que o 
sintagma deslocado é retomado por um pronome resumptivo, estruturas estas designadas de Deslocamento à Esquerda (DE) (ROSS, 1967).

Pontes (1983), a partir das reflexões de Ross (1967), discute as dificuldades de distinguir DE e Top em português. Para a autora, um empecilho para essa distinção é a possibilidade de elipse do pronome resumptivo no $\mathrm{PB}$. Para o português, muitos gramáticos consideram o pronome cópia como um pleonasmo e, por isso, pregam sua omissão. Desse modo, a escolha do uso desses pronomes gera, segundo Pontes, duas possibilidades para a interpretação das construções de tópico:

(a) que exista uma construção só, sendo o pronome opcional. Sua ocorrência seria devida a fatores como: eliminar ambiguidades, tornar mais claro o sentido; (b) que existam duas construções diferentes, com o pronome sendo opcional numa e na outra, ausente. Ou seja: a) Top. não tem pronome. b) D.E. tem pronome, mas este pode ser elidido. (PONTES, 1983, p. 123).

Pelo fato de o português permitir uma maior flexibilização na omissão do pronome, torna-se complexo definir se, em uma sentença, o tópico foi fronteado por meio de topicalização (sem pronome cópia) ou deslocamento à esquerda (com retomada pronominal). Por exemplo, em (6a), estamos claramente diante de um caso de, já que o constituinte na periferia da oração é retomado por um pronome cópia. No entanto, em (6b), na ausência de um pronome resumptivo visível, poderíamos interpretar a sentença ou como um caso de Top, em que não haveria de fato um pronome cópia, ou como um caso de, em que o pronome cópia foi elidido foneticamente mas se encontra presente sintaticamente.
a. [Aquele anel de diamante], eu ganhei ele ${ }_{i}$ do Arthur.
b. [Aquele anel de diamante], eu ganhei do Arthur.

Pontes discute ainda algumas peculiaridades do fenômeno no PB, em contraposição ao inglês. Por exemplo, seguindo Ross (1967), a autora mostra que, em inglês, ToP e DE se diferenciam no que diz respeito à possibilidade de extração a partir de um sintagma nominal complexo (SNC). Em inglês, apenas estruturas de Top não permitem esse tipo de extração, como mostra (7) (PONTES, 1983, p. 127).

${ }^{*}$ This hat I know [the boy who was wearing].

Em português, por sua vez, pode-se ter a extração a partir de um SNC, mesmo sem retomada pronominal, como exemplificado em (8). Pontes argumenta que, se o fato de não haver um pronome realmente é um indicativo de ToP, isso significa que a restrição de extração a partir de um SNC não se aplica em português para construções com ToP. Note que, com a presença de um pronome resumptivo, como em (9), a extração também é gramatical, como se espera para estruturas com DE (PONTES, 1983, p. 127).

(8) Este chapéu eu conheço [o menino que estava usando].

(9) Este chapéu $u_{i}$ eu conheço [o menino que estava usando ele $e_{i}$ ].

Para Pontes, esse tipo de contraste em relação ao inglês mostra que:

A situação em Português não é a mesma do Inglês e querer distinguir duas construções tópicas na base da presença ou ausência do pronome não é fácil, porque não 
se encontra uma diferença nítida entre as Ss com pronome e as Ss sem pronome. A opcionalidade do pronome faz com que as duas construções (se é que são duas) se confundam em nossa língua. Além disso, as restrições de Ross ou não se aplicam, ou quando se aplicam, não fica claro se podem ser explicadas como restrições à elipse de pronome, (como é o caso da restrição sobre E.C). (PONTES, 1983, p. 131).

Além disso, Pontes também menciona as discussões de Ross (1967) e Emonds (1976) de que Top e DE só ocorrem em orações principais. Em inglês, uma estrutura de é agramatical em sentenças subordinadas (10), o mesmo ocorrendo em relação a estruturas de Top (11) (PONTES, 1983, p. 131).

(10) *If [my father $]_{\mathrm{i}}$, he $\mathrm{i}_{\mathrm{i}}$ comes home late, my mother always grills him.

(11) *That [beans] he likes is now obvious.

Pontes mostra que, em português, essa restrição não se aplica, posto que há a ocorrência de sintagmas deslocados em diferentes tipos de orações subordinadas, com ou sem retomada pronominal, como pode ser ilustrado com os exemplos em (12) (PONTES, 1983, p. 133).

a. Estes pensamentos se vierem, é mister atalhá-los com presteza,

b. Mas acontece que as portas e janelas, a tinta tinha saído.

Na visão da autora, esses dados sugerem que: “Em Português, não é verdade que o tópico deva ser considerado um constituinte só da sentença mais alta. E isso também põe em xeque a afirmação de Emonds, de que D.E. e Top. são transformações ‘de raiz’” (PONTES, 1983, p. 134).

Pontes identifica que, assim como nas sentenças com pronome resumptivo, nas sem pronome o SN topicalizado também é dado pelo contexto linguístico ou pragmático. Nesse sentido, há uma grande complexidade em conceituar e distinguir o fronteamento de tópico na língua portuguesa, posto que a aparição explícita do pronome é, muitas vezes, opcional, assim como as pausas. Com vistas a trazer uma breve distinção sobre o processo de topicalização e deslocamento à esquerda, a autora declara que, em termos de tendências, a Top ocorreria em situações contrastivas, quando não houvesse pausa ou pronome, com SNs definidos ou não. Por outro lado, a estrutura com DE se dá em contextos não-contrastivos, com pronome-cópia, pausa e SNs definidos.

Já em termos de discurso, Pontes entende que: “Top. é que poderia ser considerada como de mudança de tópico. Usa-se Top. para mudar de um tópico para outro, contrastando com o anterior, mas relacionado com ele. D.E. é usado para dar continuidade ao discurso, sua função é eminentemente coesiva” (PONTES, 1983, p. 146).

Contudo, a autora assume que essa distinção ainda é prematura, havendo, portanto, necessidade de se estudar mais esses fenômenos no âmbito do discurso. Assim, em virtude da "nebulosidade" do fenômeno, Pontes conclui que é preciso desenvolver mais estudos sobre as condições de licenciamento de tópicos em língua portuguesa, assim como as de elisão de pronomes, para, depois, criar bases para a distinção de Top e DE. 


\section{OBJETO NULO NO PORTUGUÊS BRASILEIRO}

Em sua tese, Cyrino (1994) faz uma ampla discussão sobre o objeto nulo no português brasileiro. O termo objeto nulo refere-se ao apagamento fonológico do objeto direto em uma sentença. Embora abarque vários fenômenos, de um modo geral, pode-se dizer que o objeto nulo sempre se refere a um NP do discurso anterior, havendo, portanto, um caráter "fórico" influenciando seu uso, seja por meio de pronominalização ou elipse de VP.

Cyrino declara que as diferenças entre o português do Brasil e o português europeu, quanto ao fenômeno do objeto nulo, estão relacionadas a alterações na fixação de parâmetros, como consequência de uma mudança diacrônica. Seguindo Roberts (1993 apud CYRINO, 1994, p. 195), a mudança diacrônica acerca do objeto nulo no PB se dá em três fases. Inicialmente, houve uma mudança fonológica no século XVII, o que fez com que o clítico de terceira pessoa fosse eliminado em certos contextos. De certa forma, isso propiciou o crescente uso da elipse sentencial no século XVIII. Por conseguinte, no século XIX, a criança passou a estender ao objeto, cujo antecedente é [+específico/referencial, -animado], a possibilidade de reconstrução em $\mathrm{FL}^{1}$ e elipse em $\mathrm{FF}^{2}$. Aumentou-se assim a ocorrência de objetos nulos em quaisquer estruturas no PB.

Ao lado de estruturas com clíticos sentenciais (13), as crianças do século XVII até o XIX ouviam também frases que eram compostas pela elipse sentencial (14) (CYRINO, 1994, p. 196-197). Essa inovação deu-se por meio de reanálises de estruturas simples, que abordam elipse sentencial como respostas curtas.

(13) “... o homem do alecrim levou um capote com que estava coberto” "E como o levou?”

"Pois como há aqui outro, fora D. Fuas?"

"Eu não sei , em minha consciência, que é má”3

Para a autora, esses dados sugerem que o decrescente uso do clítico de terceira pessoa gerou o crescimento das elipses sentenciais, especialmente com verbos preposicionais. As crianças passaram a utilizar o objeto nulo em todos os casos em que os antecedentes eram [+específico/ referencial, -animado], inclusive os não sentenciais. Com isso, conforme mostrado por Cyrino, entre os séculos XVII-XIX, as crianças poderiam produzir tanto sentenças como (15a), com clítico, quanto sentenças como (15b), sem clítico (CYRINO, 1994, p. 197).

a. E como o levou?

b. E como levou __ ? (i.e., E como levou [o capote]?)

Isso leva Cyrino a afirmar que:

A mudança paramétrica, a fase em que certas estruturas deixam de existir na gramática, está completa nos textos do século XX Essa mudança estaria estampada

\footnotetext{
${ }^{1} \mathrm{FL}$ : forma lógica.

${ }^{2} \mathrm{FF}$ : forma fonética.

${ }^{3}$ Esse exemplo de estrutura com elipse sentencial teria o seguinte formato no conceito linguístico de forma lógica (FL): "Eu não sei |como há aqui outro, fora D.Fuas|, em minha consciência, que é má”.
} 
na falta do pronome clítico neutro e do clítico “o” para antecedentes |-animado|, o que altera o paradigma dos pronomes acusativos do PB. (CYRINO, 1994, p. 198).

Considerando as fases de mudança dos pronomes acusativos clíticos e não clíticos do PB, propostas por Kato (1991), Cyrino acredita que o PB está na fase 3 de mudança, isto é, não há mais clítico zero para a terceira pessoa; pronomes tônicos ocupam o lugar dos clíticos na posição de objetos definidos, nas segunda e terceira pessoas; e os acusativos de terceira pessoa estão em desuso, sendo substituídos por objetos nulos para antecedentes [- animados] e por pronomes tônicos para os outros tipos de antecedentes.

Assim sendo,

[...] o português que chegou ao Brasil apresentava dois tipos de objetos nulos: a) possivelmente, variáveis - mas ver Kato 1991a- para antecedentes NP |+especifico|, visto a não-ocorrência em ilhas, e b) reconstrução de DP/NP para NPs |-específico|, visto a ocorrência em qualquer tipo de contexto. Além disso, apresentava a elipse sentencial, analisada, em minha proposta, como estrutura de reconstrução de DP/NP em FL. A emergência do objeto nulo no PB, isto é, a mudança diacrônica, ocorreu quando a possibilidade da ocorrência do processo "reconstrução em FL e “inaudibilia” em FF, isto é, elipse, se estendeu para a objetos cujo antecedente era |-animado|. (CYRINO, 1994, p. 200).

Com base nessas argumentações, Cyrino conclui sua retrospectiva história sobre a evolução do objeto nulo alegando que, como houve uma mudança fonológica no século XVII, as pessoas passaram a dizer a mesma coisa com ou sem o uso dos clíticos ao se referirem à terceira pessoa - em elipses sentenciais. Isso fez com que o falante optasse pela "inaudibilia”, como forma de evitar situações que não permitem próclise do clítico de terceira pessoa. Já no século XVIII, vê-se um grande aumento da elipse sentencial, ou seja, "um maior número de estruturas onde o que se ‘ouve’ é a elipse” (CYRINO, 1994, p. 200). Por conseguinte, no século XIX, a produção de objetos nulos específicos com antecedente [-animado] e de elipses sentenciais pelas crianças - como resultado de "reconstruções" em FL - indicam novamente "o aumento na opção ‘nulo’ vs. ‘clítico’” (CYRINO, 1994, p. 200). Além disso, conforme a autora, tem-se também o surgimento do pronome tônico como possibilidade de realização do objeto. Todos esses fatos mostram porque a mudança diacrônica se deu no PB:

[...] em PB, devido a uma alteração fonológica e à escolha de uma das opções oferecidas pela sintaxe da língua, obscureceu-se a evidência positiva necessária para a criança determinar a gramática. A partir da falta de evidência robusta, a criança inovou as possibilidades de objeto nulo no $\mathrm{PB}$ e, consequentemente, houve uma mudança no paradigma pronominal da língua. (CYRINO, 1994, p. 200-201).

Em suma, essa mudança paramétrica pode ser visualizada na alteração do paradigma pronominal do século XX, em que “[...] não existe mais o clítico neutro, este sendo substituído pelo objeto nulo, e os outros clíticos de $3^{\text {a }}$. pessoa sendo substituídos também, ou pelo objeto nulo, ou pelo pronome tônico” (CYRINO, 1994, p. 201). 


\section{FRONTEAMENTO DE ARGUMENTO}

Haegeman (2006) entende que a não ocorrência de topicalização e focalização em inglês, em tipos específicos de cláusulas, é fruto de uma estrutura empobrecida do domínio CP. A proposta é que esses fenômenos de fronteamento dependem da Força Ilocucionária, já que, para a autora, orações adverbiais centrais não permitem o fronteamento de argumento em virtude de não possuírem núcleo funcional ForceP, enquanto orações adverbiais periféricas permitem.

Haegeman (2012) retoma a questão, trazendo novas contribuições para a explicação do fronteamento em cláusulas adverbiais na língua inglesa. A autora mostra que, em inglês, um elemento "wh" frontal em orações adverbiais temporais não pode preceder um argumento periférico topicalizado (16), mas pode aparecer à esquerda de um adjunto adverbial (17). Em contrapartida, em uma língua românica como o francês, um elemento "wh" pode preceder um argumento fruto de CLLD (18) (HAEGEMAN, 2012, p. 195).

(16) * [When] her regular column she began to write last year, I thought she would be $\mathrm{OK}$.

(17) [When] last year she began to write her regular column, I thought she would be OK.

(18) [Quand] cette chanson je l'ai entendue,

Haegeman justifica os dados em (16) a (18) argumentando que sintagmas topicalizados via movimento criam ilhas, isto é, estruturas sintáticas que bloqueiam o movimento de outro constituinte. Assim, a presença de um argumento fronteado impediria o movimento do operador interrogativo e/ou relativo “wh” para a periferia da sentença. Já adjuntos e constituintes CLLD não funcionariam como ilhas e, por extensão, não bloqueariam o movimento do operador relativo e/ou interrogativo.

Em orações subordinadas adverbiais condicionais, observam-se as mesmas restrições. Orações condicionais resistem a operações de fronteamento (19), mas permitem a presença de adjuntos adverbiais na periferia da estrutura subordinada (20). Em francês, o fronteamento por CLLD não sofre restrições em orações condicionais (21) (HAEGEMAN, 2012, p. 217).

(19) "If these exams you don't pass, you won't get the degree.

(20) If on Monday the share price is still at the current level then clearly their defence doesn't hold much water.

(21) Si ce livre tu le trouves à la Fnac, achète-le.

A autora mostra também que as orações condicionais podem ser divididas em centrais e periféricas. As centrais, como exemplificado em (19), comunicam necessariamente uma condição para a realização do evento expresso pela oração principal. Já as periféricas, ou ainda, condicionais de premissa, são aquelas em que a cláusula introduzida por "if" é um pré-requisito para o ato de fala contido na oração principal (22). Note ainda que, conforme o exemplo ilustrativo para orações periféricas, estas permitem topicalização, ao contrário das condicionais centrais (HAEGEMAN, 2012, p. 232).

(22) If some precautions they have indeed taken, many other possible measures they have continued to neglect. 
Haegeman explica esse contraste entre condicionais centrais e periféricas argumentando que, nas centrais, há um operador que se desloca de TP para CP. Assumindo a periferia cindida de Rizzi (1997), em uma sentença como (19), o fronteamento do argumento "these exams" para uma projeção TopP é agramatical, visto que isso impediria a passagem do operador nulo para [Spec,ForceP], por exemplo, onde seria estabelecida uma relação especificador-núcleo com o complementizador "if” (cf. a representação em (23)). Nas periféricas, a proposta é que essas estruturas, por não apresentarem uma condição, e sim um pressuposto, não contêm um operador condicional nulo que precise se mover do domínio de TP para a periferia da oração subordinada. Assim, em um exemplo como (22), o fato de não haver movimento de operador permite o fronteamento de um argumento, o que explica a gramaticalidade de topicalização nas condicionais periféricas (cf. a representação em (24)).

$$
\begin{aligned}
& { }^{*}\left[_{\text {ForceP }} \mathrm{OP}_{\mathrm{i}} \text { if }{ }_{\text {+Force }}\left[{ }_{\text {TopP }} \mathrm{XP}_{\mathrm{s} \text { Top }}\left[\mathrm{TP}_{\text {TP }} \ldots \mathrm{t}_{\mathrm{s}} \ldots \mathrm{t}_{\mathrm{i}}\right]\right]\right] \\
& {\left[_{\text {ForceP }} \text { if }_{\text {+Force }}\left[{ }_{\text {TopP }} \mathrm{XP}_{\mathrm{s} \text { Top }}\left[{ }_{\text {TP }} \ldots \mathrm{t}_{\mathrm{s}} \ldots\right]\right]\right]}
\end{aligned}
$$

Em relação à possibilidade de fronteamento de adjuntos em condicionais centrais, como ilustrado em (20), Haegeman argumenta que, neste caso, isso é possível pois o adjunto é gerado diretamente na periferia da oração. Nesse sentido, como ele não se move para o sistema CP, consequentemente não é criada uma barreira para o alçamento do operador condicional nulo (cf. a representação em (25)). O mesmo se aplica para os casos de fronteamento via CLLD. Assim como adjuntos, um tópico CLLD é gerado diretamente na periferia da sentença (CINQUE, 1990). Isso significa, portanto, que um constituinte CLLD não impede o movimento do operador condicional nulo, fazendo com que o deslocamento à esquerda clítica seja possível em orações adverbiais de línguas românticas (cf. a representação em (26)).

$$
\begin{aligned}
& {\left[_{\text {ForceP }} \mathrm{OP}_{\mathrm{i}} \text { if }_{+ \text {Force }}\left[{ }_{\text {TopP }} \mathrm{XP}_{\text {adjunct Top }}\left[\left[_{\mathrm{TP}} \ldots \mathrm{t}_{\mathrm{i}}\right]\right]\right]\right.} \\
& {\left[\text { ForceP } \mathrm{OP}_{\mathrm{i}} \mathrm{si}_{+ \text {Force }}\left[{ }_{\mathrm{TopP}} \mathrm{XP}_{\text {CLLD Top }}\left[{ }_{\mathrm{TP}} \ldots \mathrm{t}_{\mathrm{i}}\right]\right]\right]}
\end{aligned}
$$

Em português, ao contrário do inglês, o fronteamento de argumentos é licenciado tanto em condicionais centrais quanto em condicionais periféricas, como mostram os dados em (27) e (28), respectivamente.

(27) Se a mesma proposta o outro candidato fizer, ele não vai obter essa posição. (central)

(28) Se a mesma proposta o outro candidato tivesse feito, ele não teria obtido essa posição. (periférica)

Esses exemplos mostram que a “topicalização” sem retomada resumptiva do PB se afasta da topicalização do inglês e se aproxima da CLLD das línguas românicas. Isso posto, surgem os seguintes questionamentos: por que o português permite o fronteamento de argumento na periferia à esquerda de orações centrais condicionais introduzidas por "se", sendo que, no inglês, isso não é possível? Esse constituinte se movimenta para a periferia (topicalização) ou é gerado diretamente no sistema CP, tal como o processo de CLLD, mas sem ser retomado por um pronome visível? Essas duas hipóteses são representadas em (29) e (30).
a. Hipótese 1: o argumento é movido de uma posição interna ao TP
b. $\left[_{\mathrm{CP}} \mathrm{XP}_{\mathrm{i}}\left[_{\mathrm{TP}} \ldots t_{\mathrm{i}} \ldots\right]\right.$ 
a. Hipótese 2: o argumento é gerado no sistema CP, sendo retomado por um pronome nulo.

b. $\left[{ }_{\mathrm{CP}} \mathrm{XP}_{\mathrm{i}}\left[_{\mathrm{TP}} \ldots\right.\right.$ pro $\left._{\mathrm{i}} \ldots\right]$

Se afirmarmos que o argumento fronteado se movimentou para a periferia da sentença por processo de topicalização, como esquematizado na hipótese 1, não é possível aplicar a proposta de Haegeman (2012) para o PB. Desse modo, em vez de termos um princípio universal em que o alçamento de um operador condicional nulo é bloqueado em contextos de topicalização, como se depreende da proposta de Haegeman (2012), os fatos do português revelariam uma propriedade sujeita à variação entre as línguas naturais. Por sua vez, a hipótese 2 permite entender a análise de Haegeman (2012) como algo que se aplica de modo universal entre as línguas. Assim, o aparente caso de violação no PB nada mais é do que uma construção com tópico CLLD (retomado por um pronome nulo), e não uma estrutura de topicalização.

Ainda sobre as hipóteses para a possibilidade de fronteamento de argumento no PB, Guesser e Mioto (2016) sugerem que o fronteamento sem retomada pronominal no PB corresponde a uma estrutura de CLLD em que a retomada do tópico é feita por um resumptivo nulo. Contudo, eles também apontam algumas evidências que colocam em xeque a aceitação de que o constituinte de retomada do elemento topicalizado seja de fato uma versão nula do pronome clítico de uma CLLD.

Segundo os autores, em grande parte das línguas românticas, os constituintes tipicamente são fronteados à esquerda por meio de CLLD (31a) e $\mathrm{HT}^{4}$ (31b), como é o caso do italiano. Por outro lado, em língua portuguesa, o processo de topicalização à esquerda pode ocorrer sem retomada pronominal, como pode ser visualizado nos exemplos em (32), retirados do trabalho de Guesser e Mioto (2016, p. 90-91).

a. Gianni, ${ }_{\mathrm{i}}$ lo ho visto ieri.

b. Gianni, non gli ho ancora parlato.

a. O teu livro, eu comprei.

b. Para a noiva, o João vai dar flores (não um relógio).

Guesser e Mioto problematizam o fenômeno de topicalização à esquerda sem retomada pronominal no $\mathrm{PB}$, alegando que parece não ser tão claro qual é o processo existente nesses casos: seria um caso de topicalização do tipo do inglês ou uma estrutura semelhante a uma CLLD? Tomando como suporte as premissas de Haegeman (2012), os autores chegam à conclusão de que o fronteamento sem pronome resumptivo no PB se distancia da topicalização inglesa e se aproxima da CLLD românica, em que a retomada não é foneticamente realizada.

Indo um pouco mais além, Guesser e Mioto mencionam Kato (2011), a qual propõe que a topicalização sem pronome resumptivo é um tipo de CLLD com clítico nulo, como é esquematizado em (33) (GUESSER; MIOTO, 2016, p. 97).

As flores, o João vai dar [clø [ $\left.\left.t_{\mathrm{i}}\right]\right]$ para a noiva.

\footnotetext{
${ }^{4} \mathrm{O}$ tópico CLLD (Clitic Left Dislocation) e o tópico HT (Hanging topic) se distinguem em alguns pontos. Quando um argumento preposicionado é fronteado, na CLLD, o tópico aparece como PP (ex. Pro João, a Maria vai lhe dar um livro); já na HT, o tópico se manifesta como DP (ex. O Pedro, a Maria vai lhe dar um livro). Além disso, pronomes tônicos podem aparecer como resumptivos em HT.
} 
Contrariando essa proposta, Guesser e Mioto mostram que, no PB, nem sempre se pode omitir o clítico, como o contraste em (34) mostra (GUESSER; MIOTO, 2016, p. 98).

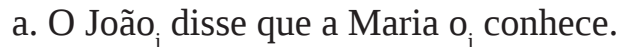
b. * ${ }^{*}$ João $_{\mathrm{i}}$ disse que a Maria $\emptyset_{\mathrm{i}}$ conhece.

Essa seria, portanto, a primeira evidência de que, no PB, não se pode falar de retomada por clítico nulo em todos os casos. Além disso, Guesser e Mioto declaram que a necessidade de retomada explícita obrigatória em estruturas $\mathrm{HT}$ do $\mathrm{PB}$, seja por meio de um pronome clítico ou forte (tônico), sugere que a topicalização sem retomada resumptiva no PB não significa necessariamente a retomada do tópico por um clítico nulo, como afirmou Kato (2011). Em alguns casos, o pronome resumptivo é obrigatório, como pode ser visto em (35) (GUESSER; MIOTO, 2016, p. 98).

(35) $\quad{ }^{*} \mathrm{O}$ Pedro $_{\mathrm{i}}$, o João vai dar flores $e c_{\mathrm{i}}$.

A partir desses dados, os autores propõem então que, embora sejam válidas as evidências que apontam para a existência de CLLD com retomada por um pronome foneticamente nulo no PB, deve-se questionar a especificação gramatical desse elemento resumptivo nulo, já que, aparentemente, ele não será um clítico nulo em todos os casos. Guesser e Mioto (2016, p. 99) concluem o seu texto afirmando que, em estudos futuros, necessita-se averiguar se a falta de intercambialidade entre ocorrências com clítico visível e nulo pode ser atribuída "(i) a alguma propriedade sintática específica dessas estruturas, (ii) a alguma diferença sintática/derivacional entre um clítico e sua versão invisível ou (iii) à combinação de ambos os fatores”.

\section{ANÁLISE E DISCUSSÃO}

Como já apresentado, o objetivo deste artigo é verificar se os argumentos ${ }^{5}$ fronteados na periferia à esquerda de orações condicionais são fruto de deslocamento à esquerda clítica ou topicalização. Na seção anterior, apresentamos a análise de Haegeman (2012), que explica a impossibilidade de se frontear argumentos em orações condicionais da língua inglesa. Para a autora, há uma distinção entre os argumentos oriundos de CLLD em línguas românicas e a topicalização de argumentos no inglês. Como mostramos, o processo de CLLD tem um comportamento mais livre que o tópico fronteado por movimento. A ideia central de Haegeman é que, nas condicionais centrais, por apresentarem um operador nulo que se movimenta de TP para CP, o fronteamento de argumento criaria uma ilha que inibiria a passagem do operador, tornando, assim, a sentença agramatical, a exemplo da oração vista em (19). Nesse sentido, a proposta da autora é que um argumento topicalizado cria um efeito de intervenção para o movimento do operador da sentença condicional. Em contrapartida, as orações condicionais periféricas não apresentam esse operador; logo, o movimento do argumento não é empecilho para a boa formação da sentença.

Apresentando um comportamento distinto ao da língua inglesa, os argumentos em PB podem aparecer na periferia da sentença de orações condicionais centrais (37-40) e periféricas

\footnotetext{
${ }^{5} \mathrm{Na}$ sintaxe gerativa, argumento é o complemento, obrigatório ou facultativo, selecionado pelo verbo ou previsto na sua estrutura argumental. Desse modo, são argumentos os sintagmas que desempenhem a função de sujeito, objeto direto, objeto indireto, predicativo do sujeito, predicativo do objeto direto e oblíquo com estatuto de complemento. Para essa análise, em especial, consideramos apenas os argumentos que correspondem ao objeto direto e indireto.
} 
(36 e 41). Esses argumentos podem ser formados por diferentes combinações morfológicas, tais como determinante + nome (36), preposição + pronome (37), preposição + DP lexical (38), determinante + pronome + nome (39), pronome + nome (40), ou, ainda, apenas um nome (41).

$$
\text { Se ao menos o contrato ele tivesse assinado, estaríamos ricos agora. }
$$

Se pra você eu der o carro, fique contente.

Se com os alunos a professora brigar, ela vai ser demitida.

No padrão tradicional de organização das orações, a ordem linear usual é "sujeito-verbo-complemento”. Contudo, nos exemplos anteriores (36-41), vê-se que os elementos que formam os argumentos foram fronteados, isto é, colocados em uma posição à frente da de costume.

De antemão, apenas olhando para as frases, pode-se dizer que houve uma topicalização em cada exemplo, ou seja, o argumento nasceu em uma posição pós-verbal e foi movimentado para a periferia da sentença. Isso poderia ser justificado inclusive pela não existência de um elemento pronominal resumptivo retomando o argumento fronteado. Contudo, em virtude do português brasileiro ser uma língua mais suscetível à presença de objetos nulos, questiona-se se não há, em cada exemplo, um argumento que nasceu na própria periferia da sentença, sendo fruto, portanto, de deslocamento à esquerda clítica (Clitic Left Dislocation - CLLD) com retomada pronominal nula.

Como já visto nos pressupostos de Cyrino (1994), houve um processo diacrônico de erosão do sistema de uso dos clíticos no PB. Hoje, opta-se muitas vezes pelo uso de pronomes tônicos ou ainda pela omissão fônica do objeto. Poucos clíticos restaram no uso, como é o caso dos pronomes “me” e “te”, na fala, e dos “o” e "lhe”, na escrita. Isso poderia justificar, então, o motivo pelo qual não há retomada pronominal de argumentos fronteados nos exemplos anteriores. Talvez seja essa maior amplitude de opções para o uso de objeto nulo que faz com que os processos de Topicalização e CLLD se confundam no português brasileiro, diferentemente do que acontece na língua inglesa, em que existem maiores restrições no tocante a processos de elipse (seja de sujeito, seja de objeto).

Essa possibilidade de omitir-se o objeto fornece-nos subsídios para acreditar que, em orações subordinadas condicionais do $\mathrm{PB}$, o argumento fronteado é um tópico CLLD, isto é, um constituinte nascido diretamente na periferia da sentença e retomado por um pronome correferente localizado no interior de TP. Esse pronome resumptivo poderia ser um pronome clítico (42), tônico (43) ou ainda um objeto pronominal nulo (44).

Se pra você $\hat{i}_{i}$ eu $\mathbf{t e}_{\mathrm{i}}$ contar o segredo, fique em silêncio.

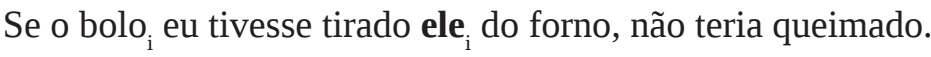

Se o bolo eu tivesse tirado pro $_{i}$ do forno, não teria queimado.

Somando então essa evidência do objeto nulo à hipótese de Haegeman (2012), já descrita anteriormente, pode-se supor que, no português, os argumentos fronteados, inclusive os sem aparente retomada pronominal, nascem na própria periferia da sentença em orações condicionais, sendo originados, portanto, por meio de CLLD. Por serem gerados diretamente no sistema CP, o 
alçamento do operador condicional nulo não é bloqueado nas orações subordinadas adverbiais condicionais.

É importante averiguar, porém, se todos os casos de fronteamento de argumento possibilitam realmente uma retomada pronominal clítica ou tônica, com vistas a verificar-se se os objetos nulos podem ser sempre substituídos por pronomes explícitos. Se nem todos os casos puderem ser retomados por pronomes visíveis, pode-se sugerir que há também topicalização em orações condicionais no PB, o que desconstruiria em parte a análise feita até aqui. Por outro lado, se todos os casos apresentarem a possibilidade de inserção de um elemento explícito na posição de objeto nulo, é porque no PB o fronteamento de argumento em orações condicionais centrais se dá apenas por CLLD. O Quadro 1 mostra que a retomada pronominal sempre é possível nessas estruturas com argumentos fronteados.

Quadro 1: Substituição do elemento resumptivo nulo por um pronome visível

\begin{tabular}{|c|c|c|}
\hline & $\begin{array}{c}\text { Fronteamento de argumento sem } \\
\text { retomada pronominal visível }\end{array}$ & $\begin{array}{l}\text { Fronteamento de argumento } \\
\text { com retomada visível }\end{array}$ \\
\hline $\mathrm{DET}+\mathrm{NOM}$ & $\begin{array}{l}\text { Se a Melissa você magoar, eu } \\
\text { não respondo por mim. }\end{array}$ & $\begin{array}{l}\text { Se a Melissa você magoar ela, } \\
\text { eu não respondo por mim. }\end{array}$ \\
\hline NOM & $\begin{array}{l}\text { Se chucrute você fizer com } \\
\text { pimenta, deixe esfriar por } 10 \\
\text { minutos. }\end{array}$ & $\begin{array}{c}\text { Se chucrute você fizer ele com } \\
\text { pimenta, deixe esfriar por } 10 \\
\text { minutos. }\end{array}$ \\
\hline $\mathrm{DET}+\mathrm{PRON}+\mathrm{NOM}$ & $\begin{array}{l}\text { Se a sua vida você deixar passar, } \\
\text { não terá tempo para amar. }\end{array}$ & $\begin{array}{c}\text { Se a sua vida você deixar ela } \\
\text { passar, não terá tempo para } \\
\text { amar. }\end{array}$ \\
\hline PRON + NOME & $\begin{array}{c}\text { Se minha bicicleta você quebrar, } \\
\text { vai ter que me pagar outra. }\end{array}$ & $\begin{array}{l}\text { Se minha bicicleta você quebrar } \\
\text { ela, vai ter que me pagar outra. }\end{array}$ \\
\hline PREP + DP LEXICAL & $\begin{array}{l}\text { Se do Carlos eu não gosto, o } \\
\text { problema é meu. }\end{array}$ & $\begin{array}{c}\text { ?Se do Carlos eu não gosto dele, } \\
\text { o problema é meu. }{ }^{6}\end{array}$ \\
\hline PREP + PRON & $\begin{array}{c}\text { Se pra você eu contar o segredo, } \\
\text { fique em silêncio. }\end{array}$ & $\begin{array}{l}\text { Se pra você eu te contar o } \\
\text { segredo, fique em silêncio. }\end{array}$ \\
\hline
\end{tabular}

Fonte: Os autores.

A possibilidade de preencher os objetos nulos com pronomes visíveis comprova a teoria até aqui apresentada: argumentos fronteados na periferia à esquerda de orações condicionais centrais sem retomada pronominal visível nascem na própria periferia e são retomados por um elemento pronominal nulo. Em alguns casos o pronome resumptivo pode indicar uma repetição

\footnotetext{
${ }^{6}$ Para falantes que não aceitam esse tipo de exemplo, o nível de aceitabilidade melhora se o argumento fronteado não estiver preposicionado, como em (i):

(i) Se o Carlos eu não gosto dele, o problema é meu.
} 
bastante explícita. Contudo, embora o objeto nulo seja mais viável no português, dadas as suas motivações linguísticas e extralinguísticas, a possibilidade de substituir-se o objeto nulo por um pronome pode ser considerada uma evidência bastante válida para comprovar-se a existência de um tópico CLLD nessas estruturas.

Além disso, é oportuno destacar que a natureza gramatical dos argumentos fronteados não alterou a possibilidade de elisão e nem de retomada pronominal nos exemplos do Quadro 1, o que é bastante válido. De modo semelhante, percebe-se que a especificação modo-temporal das construções condicionais também não interferiu no desempenho do fenômeno de fronteamento nessas estruturas.

Apresentamos, no Quadro 2, uma rápida análise sobre os subtipos das orações condicionais: (i) condicionais factuais; (ii) condicionais contrafactuais; (iii) condicionais eventuais.

Quadro 2: O fronteamento de argumento nos subtipos das condicionais

\begin{tabular}{|c|c|c|}
\hline Os subtipos das condicionais ${ }^{7}$ & $\begin{array}{l}\text { Fronteamento de argumento } \\
\text { com retomada pronominal nula }\end{array}$ & $\begin{array}{c}\text { Fronteamento de argumento } \\
\text { com retomada pronominal } \\
\text { visível }\end{array}$ \\
\hline $\begin{array}{c}\text { Oração condicional factual } \\
\text { Dada a realização/a } \\
\text { factualidade da oração } \\
\text { condicionante, segue-se, } \\
\text { necessariamente, a realização/ } \\
\text { factualidade da oração } \\
\text { condicionada }\end{array}$ & $\begin{array}{l}\text { Se do feijão eu não gosto, então } \\
\text { o problema é meu. } \\
\text { Se o prêmio você ganhou, então } \\
\text { é porque você é merecedora } \\
\text { dessa vitória. }\end{array}$ & $\begin{array}{l}\text { Se do feijão eu não gosto dele, } \\
\text { então o problema é meu. } \\
\text { Se o prêmio você ganhou } \\
\text { ele, então é porque você é } \\
\text { merecedora dessa vitória. }\end{array}$ \\
\hline $\begin{array}{c}\text { Oração condicional } \\
\text { contrafactual } \\
\text { Dada a não realização/ } \\
\text { não factualidade da oração } \\
\text { condicionante, assegura- } \\
\text { se, necessariamente, a não } \\
\text { realização/ não factualidade da } \\
\text { oração condicionada }\end{array}$ & $\begin{array}{l}\text { Se a maturidade de hoje eu } \\
\text { tivesse naquela época, não teria } \\
\text { errado tanto. } \\
\text { Se outras escolhas eu tivesse } \\
\text { feito, como seria minha vida } \\
\text { hoje? }\end{array}$ & $\begin{array}{l}\text { Se a maturidade de hoje eu a } \\
\text { tivesse naquela época, não teria } \\
\text { errado tanto. } \\
\text { Se outras escolhas eu as tivesse } \\
\text { feito, como seria minha vida } \\
\text { hoje? }\end{array}$ \\
\hline $\begin{array}{c}\text { Dada a potencialidade } \\
\text { da oração condicionante, } \\
\text { segue-se a eventualidade da } \\
\text { condicionada }\end{array}$ & $\begin{array}{c}\text { Se o arroz ela queimar, será } \\
\text { desclassificada do programa de } \\
\text { culinária. }\end{array}$ & $\begin{array}{l}\text { Se o arroz ela queimar ele, será } \\
\text { desclassificada do programa de } \\
\text { culinária. }\end{array}$ \\
\hline
\end{tabular}

Fonte: Os autores.

\footnotetext{
${ }^{7}$ Para fazer-se a distinção entre esses subtipos, utilizaram-se os pressupostos teóricos de Neves (2011).
} 
Normalmente, as condicionais são definidas por: “se p, (então) q”, em que $p$ é a prótase (condição para realização - oração condicional) e $q$ é a apódose (consequência/resultado da resolução da condição enunciada - oração principal/nuclear). Sobre isso, vê-se que o Quadro 2 é muito significativo, pois mostra com bastante evidência que todos os subtipos das construções condicionais podem apresentar fronteamento de argumento, seja ele com retomada nula ou visível. A indicação modo-temporal que, de certa forma, norteia a factualidade e eventualidade das orações condicionais não é empecilho para o fenômeno linguístico que estamos estudando neste trabalho. Pelo contrário, a possibilidade de frontear-se argumento nos três subtipos de condicionas (com ou sem retomada visível) pode ser considerada uma evidência de que, no português brasileiro, o fronteamento de argumento na periferia à esquerda de orações condicionais dá-se por meio de CLLD.

Fazendo uma comparação entre nomenclaturas, pode-se dizer que as orações condicionais centrais de Haegeman (2012) são as eventuais de Neves (2011), já que são elas que dão uma condição para a realização do evento expresso na oração principal. Há nas centrais/eventuais uma potencialidade a ser posta em xeque para a ocorrência da matriz. Por outro lado, as orações condicionais periféricas de Haegeman (2012) podem ser comparadas às factuais e contrafactuais de Neves (2011), dado que apresentam pressupostos.

É interessante destacar que, tanto no Quadro 1 como no Quadro 2, foram usados exemplos de orações centrais e também de orações periféricas; e em todos os casos pôde-se retomar o argumento fronteado por meio de um pronome resumptivo. Isso pode mostrar que, embora no inglês não haja restrição para a topicalização de argumento em orações periféricas, no PB, essas construções podem se dar tanto por topicalização como também por CLLD. O deslocamento à esquerda clítica com retomada nula ou visível se encaixa em qualquer tipo de oração condicional no PB, aparentando ser, assim, muito mais flexível do que a topicalização. É preciso fazermos um estudo mais aprofundado quanto ao caso das orações periféricas, a fim de identificarmos se no PB há só CLLD ou também topicalização, como no inglês. Essa discussão deixamos, porém, para trabalhos futuros.

Na sequência, uma outra questão interessante a ser discutida ainda nesse tópico analítico é, justamente, aquilo que Guesser e Mioto (2016) pontuaram sobre a omissão do clítico. Para mostrar que nem sempre o clítico pode ser omitido, apresentamos novamente o exemplo (34b), retomado agora como (45) (GUESSER; MIOTO, 2016, p. 98).

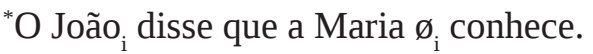

De fato, em uma sentença como essa, a omissão seria inviável. Contudo, se pensarmos esse exemplo dentro de uma construção adverbial condicional, notamos que o objeto pode ser ocultado sem prejuízos para a gramaticalidade da estrutura (46 - periférica, e 47 - central). Isso prova novamente que, em orações adverbiais condicionais iniciadas por "se”, argumentos podem ser fronteados com retomada nula ou explícita sem muitas restrições, por meio de CLLD.

a. Se o João eu disse que a Maria conhece, acredite em mim.

b. Se o João eu disse que a Maria conhece ele, acredite em mim.

a. Se o João ela disser que conhece, acredite.

b. Se o João ela disser que o conhece, acredite. 
Toda essa discussão nos mostra que o froteamento de argumento com retomada nula em orações condicionais centrais do PB se distancia da topicalização do inglês e se aproxima das construções de CLLD das línguas românicas. Contudo, uma observação mais atenta revela que há ainda uma certa divergência entre o funcionamento desse fenômeno no português e em outras línguas românicas. Isso ocorreria em razão de, no português, haver maior amplitude no uso do objeto nulo, enquanto, em línguas como o italiano e o francês, por exemplo, o objeto vem geralmente explícito por meio de um pronome clítico visível. Tal fato faz com que um tópico CLLD seja bem mais marcado nessas outras línguas românicas do que no português, já que, nelas, o elemento resumptivo do argumento fronteado é visível. Isso pode ser justificado como decorrente de um processo sócio-histórico de desenvolvimento da língua portuguesa, em que vemos o desuso de pronomes clíticos e o favorecimento do objeto nulo.

\section{CONSIDERAÇÕES FINAIS}

Este estudo buscou entender as razões que permitem a possibilidade de fronteamento de argumento em orações subordinadas adverbiais do português brasileiro, algo não possível em inglês, por exemplo. Para tanto, teve como objetivo averiguar qual processo rege esse fenômeno: clitic left dislocation ou topicalização. Pautando-se nas premissas de Haegeman (2012), assumimos que, em orações condicionais centrais, o fronteamento de argumento bloqueia qualquer tipo de movimento para a periferia da sentença, impossibilitando a passagem do operador nulo condicional de TP para CP. Nossa hipótese é de que esse processo de restrição também se aplica no PB.

Mostramos que os argumentos fronteados sem retomada pronominal em português, em vez de serem entendidos como casos de topicalização, devem ser interpretados como tópicos CLLD. Nossa proposta é que, nas adverbiais condicionais, o argumento fronteado é sempre retomado, ou por uma forma pronominal visível, ou por uma forma pronominal nula. Essa análise ganha sustentação se pensarmos que o PB é uma língua em que o fenômeno do objeto nulo é altamente produtivo. Nesse sentido, então, o PB não constitui uma exceção para a análise de Haegema, já que a variante brasileira do português se comportaria de modo semelhante às línguas românicas que manifestam CLLD nas condicionais centrais. A única particularidade do PB é que o elemento resumptivo pode assumir a forma de um elemento pronominal nulo.

\section{REFERÊNCIAS}

CINQUE, G. Types of A’ dependencies. Cambridge: MIT Press, 1990.

CYRINO, S. M. L. O objeto nulo do português do Brasil: um estudo sintático-diacrônico. 1994. Tese (Doutorado em Linguística) - Universidade Estadual de Campinas, Campinas, 1994.

EMONDS, J. A transformational approach to English syntax. New York: Academic Press, 1976.

GUESSER, S.; MIOTO, C. Notas sobre a topicalização à esquerda sem retomada pronominal (explícita) no PB. In: GUESSER, Simone. (org.). Linguística: pesquisa e ensino. Boa Vista: Editora da UFRR, 2016. p. 79-102. 
HAEGEMAN, L. Argument fronting in English, Romance CLLD and the left periphery. In: ZANUTTINI, R. et al. (org.). Cross-linguistic research in syntax and semantics: negation, tense and clausal architecture. Washington, DC: Georgetown University Press, 2006. p. 27-52.

HAEGEMAN, L. Adverbial clauses, main clause phenomena, and composition of the left periphery: The cartography of syntactic structures. New York: Oxford University Press, 2012.

KATO, M. A. The distribution of pronouns and null elements in object position in Brazilian Portuguese. In: ASHBY, W. J.; PERISSINOTTO, M. M. G.; RAPOSO, E. (org.). Linguistic perspectives on the Romance languages. Amsterdam: John Benjamins, 1991. p. 225-236.

KATO, M. A. DPs complexos em estruturas de “construal”. Revista Letras, Curitiba, v. 84, n. 2, p. 141-151, 2011. DOI: http://dx.doi.org/10.5380/rel.v84i2.25613

NEVES, M. H. M. As conjunções condicionais. As construções condicionais. In: NEVES, M. H. M. (org.). Gramática de usos do português. 2. ed. São Paulo: Editora Unesp, 2011. p. 829-861.

PONTES, E. S. L. Topicalização e deslocamento para a esquerda. Cadernos de Linguística e Teoria da Literatura, [s. l.], n. 9, p. 121-151, 1983. DOI: http://dx.doi.org/10.17851/01013548.5.9.121-151

RIZZI, L. The fine structure of the left periphery. In: HAEGEMAN, L. (org.). Elements of grammar. Dordrecht: Springer, 1997. p. 281-337.

ROSS, J. Constraints on variables in syntax. 1967. Tese (Doutorado em Modern Languages and Linguistics) - Massachusetts Institute of Technology, Cambridge, Massachusetts, 1967.

Recebido em: jun. 2020.

Aceito em: ago. 2020. 